
\title{
25 Research Square \\ Utilization of Innovative Medical Technologies In German Inpatient Care: Does Evidence Matter?
}

Helene Eckhardt ( $\nabla$ helene.eckhardt@tu-berlin.de )

Technische Universität Berlin https://orcid.org/0000-0002-3921-428X

\section{Susanne Felgner}

Technische Universität Berlin

\section{Marie Dreger}

Technische Universität Berlin

\section{Sabine Fuchs}

Technische Universität Berlin

Hanna Ermann

Technische Universität Berlin

Hendrikje Lantzsch

Technische Universität Berlin

\section{Tanja Rombey}

Technische Universität Berlin

\section{Reinhard Busse}

Technische Universität Berlin

\section{Cornelia Henschke}

Technische Universität Berlin

\section{Dimitra Panteli}

Technische Universität Berlin

\section{Research}

Keywords: Evidence based decision making, evidence based medicine, value based health care, evidence development, implementation, health technology, inpatient care, hospital financing, Germany

Posted Date: November 23rd, 2021

DOI: https://doi.org/10.21203/rs.3.rs-1073528/v1

License: (9) This work is licensed under a Creative Commons Attribution 4.0 International License. Read Full License 


\section{Abstract}

Background: The reimbursement of new technologies in inpatient care is not always linked to a requirement for evidence-based evaluation of patient benefit. In Germany, every new technology approved for market was until recently reimbursable unless explicitly excluded. It was therefore unclear whether the implementation of innovative technologies is guided by scientific evidence. This work aimed to explore the relationship between clinical evidence and utilization for 25 selected technologies in German inpatient care.

Methods: Different methods were applied. A systematic search for evidence published between 2003 and 2017 was conducted in four bibliographic databases; clinical trial registries; resources for clinical guidelines; and health technology assessment - databases. Information was also collected on funding mechanisms and safety notices. Utilization was measured by hospital cases captured in claims data. The body of evidence, funding and safety notices per technology were analysed descriptively. The relationship between utilization and evidence was explored empirically using a multilevel regression analysis.

Results: The number of included publications per technology ranges from two to 498 . For all technologies, non-comparative studies form the bulk of the evidence. The number of randomised controlled clinical trials per technology ranges from zero to 19. Some technologies were utilized for several years without an adequate evidence base. A relationship between evidence and utilization could be shown for several but not all technologies.

Conclusions: This study reveals a mixed picture regarding the evidence available for new technologies, and the relationship between the development of evidence and the use of technologies over time. Although the influence of funding and safety notices requires further investigation, these results reemphasize the need for strengthening market approval standards and HTA pathways as well as approaches such as "coverage with evidence development".

\section{Background}

Health-related technological progress plays an important role in the improvement of health outcomes. Yet new technologies may also bear risks to patients and users $(1,2)$. Ever since the "Contergan (Thalidomide) Affair" in the 1950s,(3) market access for pharmaceuticals is highly regulated and generally requires extensive clinical evaluation. The approval process for new medical devices in the European context is decentralised and entails verifying the conformity of a device with the European Union (EU) regulatory framework, primarily regarding its intended use and safety. The necessity of clinical investigation to determine the efficacy and safety of new implantable or high-risk medical devices for market approval was introduced in 2007 (Directive 2007/47/EC(4)). Following repeated reports of patient harm, the Medical Device Regulation (MDR) (Regulation (EU) 2017/745(5)), which aimed to reform the EU regulatory framework on medical devices (Directive 93/42/EEC(6) and Directive 90/385/EEC(7)), 
introduced the term "clinical benefit" as a criterion for the approval of medical devices for the first time (8). In contrast, the premarket approval process by the Food and Drug Administration (FDA) in the United States (US) has required evidence from clinical trials to determine effectiveness and safety of innovative high-risk medical devices since the early 1990s (9-11).

Once they have been approved for market, the pathway to reimbursement of medical technologies in European health systems generally varies (12-14). While health technology assessment (HTA) to determine comparative (cost-)effectiveness of new technologies is often a prerequisite for pharmaceuticals in the outpatient sector, this is not always the case for other technologies or the inpatient setting (13). Innovative, high-risk and high-cost medical devices are more frequently the subject of HTA linked to reimbursement (15).

In healthcare systems paying for inpatient care using Diagnosis-Related Groups (DRG), like Germany, additional funding mechanisms may become necessary to reimburse newly approved medical devices, as their costs cannot always be adequately well reflected promptly within the DRG system. $(14,16)$ In German inpatient care, traditionally every new technology (Neue Untersuchungs- und Behandlungsmethode, NUB) has been reimbursable unless explicitly excluded by the Federal Joint Committee (FJC; § 137c German Social Code Book V [SGB V]). NUBs are new diagnosis or treatment methods that involve specific pharmaceuticals or medical devices. When such innovative, high-cost technologies cannot yet be sufficiently accounted for by an existing DRG, hospitals can apply to the German Institute for the Hospital Remuneration System for the permission to negotiate one-year, hospitalindividual extra-budgetary payments with health insurers $(17,18)$. Once these new technologies have been included in the German Operations and Procedures Classification System (17) and cost data from so-called DRG calculation hospitals has been analysed, their adequate funding is achieved either through supplementary payments considered in the annual budget-negotiations between hospitals and health insurers (fixed or negotiable), the split of an existing DRG or the creation of a new one. Fixed supplementary payments entail a uniform national price per case published in the appendix of the DRG catalogue; when a uniform national price cannot be determined, hospitals can still obtain individual (confidential) negotiable supplementary payments with a minimum amount of $€ 600$ per case (18).

Against the background of a lacking requirement for HTA prior to reimbursement and the described financial incentives, it is important for quality of care and value for money to enquire whether the implementation of innovative technologies in German inpatient care is guided by clinical evidence. Previous research on the influence of evidence or funding mechanisms on implementation and diffusion has largely focused on individual technologies (18-20) or on coverage decisions (21). The overall aim of this work is to explore the role of scientific evidence in the introduction and diffusion of selected technologies in German inpatient care. More specifically, to investigate: (i) the availability of scientific evidence regarding safety and efficacy/effectiveness of technologies at the time of introduction and its development over time; (ii) the relationship between this evidence and the utilization of technologies by hospitals; (iii) the potential influence of funding modalities and safety notices (warnings and recalls) on utilization. 


\section{Methods}

\section{Selected technologies and data on utilization}

Twenty-five technologies (NUBs) were selected for analysis based on pre-specified criteria (22). Based on the respective procedure codes, data on the number of inpatient cases per technology per year was obtained (see additional file 1 appendix 1). Each technology in the sample is characterised by the availability of at least four billing years in German inpatient care between 2005 and 2017; permission granted to negotiate, hospital-individual extra-budgetary payments for at least one year; and a high relevance for health care determined by relatively high utilization numbers. The sample was selected to include different types of utilization profiles (22).

\section{Search for information on funding, recalls and safety warnings}

Information sources on funding, recalls and safety warnings per technology are listed in additional file 1 appendix 2.

\section{Search for clinical evidence}

A systematic literature search was carried out in 2019 in PubMed, Medline (via OVID), Embase (via OVID) and the Cochrane Library. The development of search strategies for each included technology was based on the PICO framework (population, intervention, comparison, outcomes). To define search terms, appraisals by the Medical Service of the National Association of Health Insurance Funds and the procedure classification system were consulted, focusing on the intervention (technology-specific terms, product and manufacturer names) and the indication (technology specific search strategies are available upon request).

Supplementary searches were performed in the reference lists of included systematic reviews, clinical trial registries, HTA databases and clinical guideline databases (details in additional file 1 appendix 2).

EndNote X9 files were created per technology and used for duplicates removal (23), after search results were imported, and for documentation of the screening process.

\section{Selection of evidence}

General inclusion and exclusion criteria based on the PICO framework were developed to select relevant evidence for each technology (full details in additional file 1 appendix 3 table 3.1). Published and unpublished studies belonging to levels of evidence (LoE) 1 to 4 following the definition of the FJC (2. Chapter, $\S 11$ (3), procedure rules of FJC) (24) were included:

1a Systematic reviews of randomized controlled trials

1b Randomized controlled trials (RCT) 
2a Systematic reviews of non-randomized controlled trials

2b Prospective non- randomized controlled trials (N-RCT)

3 Retrospective controlled trials

4 Case-series and other single-arm trials

5 Case reports, etc.

Publications starting two years before the first documentation of hospital cases (earliest 2003) and up to 2017 were eligible for inclusion.

Evidence was selected in line with the rapid review methods of the Cochrane Collaboration (25). After duplicate removal, a random sample of $10 \%$ of citations ( $\min .100$ ) per technology was drawn via Rstudio (Version 1.4.1717). Two researchers independently screened the sample and selected relevant citations. In case of discrepancies, the inclusion and exclusion criteria were discussed and adjusted, involving a third researcher if necessary. The remaining citations were screened by one person based on the adjusted criteria. Each review step was documented as recommended by the PRISMA statement (26).

The selection of evidence following the searches in trial registries, guideline and HTA-databases, and the process of data extraction and risk of bias (RoB) assessment are described in additional file 1 appendices 4, 5 and 6 respectively.

\section{Categorization of study results}

For each publication, authors' conclusions were extracted from abstract and main text and categorised into "positive," "negative," "neutral," or "inconclusive". The rationale of categorization described in Figure 1. If no conclusion section in the main text was available, the categorization was performed based on the summary of results from the discussion section and from abstract.

\section{Synthesis and statistical analysis}

\section{Descriptive analysis}

The identified body of evidence was analysed descriptively. Each publication was considered as a separate data point. The recommendations from clinical guidelines, information on funding and safety notices were synthesised narratively for each technology and are discussed in combination with other findings.

\section{Empirical evaluation of the relationship between utilization and evidence results}

To evaluate whether utilization of a technology over time follows available clinical evidence, a new variable X, "results of available body of evidence" at year $t$ and technology $j$, was aggregated. The variable incorporates all identified comparative analyses (LOE 1-3) of a technology published up to and 
including year $t$, weighted by category of study results (positive, negative, neutral) and LoE. The variable depicts the prevailing results of the body of evidence available starting two years before the beginning of utilization in Germany cumulated over all years of utilization until year t. Data for the outcome variable "utilization" is represented by number of hospital cases per year $t$ and technology $\mathrm{j}$.

Due to the clustered data structure and to account for technology-specific effects, a mixed effects model (multilevel model) for two levels of data was applied $(27,28)$ and is described in additional file 1 appendix 7. The aim of the regression function is to estimate whether the development of utilization follows the direction of study results, but not to explain the whole variance; this would not be possible by including only one explanatory variable, but most other potentially influencing factors (29) are difficult to quantify.

\section{Results}

\section{Results of evidence search}

All searches yielded citation numbers in the four-digit range. The number of publications included in the final analysis (LoE 1-4) ranges from two (drug-coated balloon catheter in abdominal vessels - DCB-AV) to 498 (transcatheter aortic valve implantation - TAVI) (figure 2). Additional file 1 appendix 8 table 8.1 shows the results of the searches and screening by technology, bibliographic database, and step within the selection process.

Results of searches for grey literature (clinical guidelines, HTA reports, trial registry entries and safety notifications) are presented in additional file 1 appendix 8 table 8.2. Across technologies and years, 40 HTA reports, and 40 clinical guidelines were identified. The number of HTA reports per technology varies between zero and 12. Clinical guideline recommendations were identified for 19 technologies; the number of guidelines (and their updates) varies between one and 13 (fluorescence-assisted transurethral resection - F-TUR clinical guideline with 12 annual updates between 2006 and 2017). Further results on clinical guidelines are presented in additional file 1 appendix 12 .

At least one safety notification was identified for 12 technologies in Germany and for two further technologies internationally. The number of safety notifications in Germany ranges from one (pumpless extracorporeal lung assist/ interventional lung assist - PECLA/iLA) to 12 (TAVI). Internationally, TAVI and bioresorbable vascular scaffold in coronary vessels (BVS) are the technologies with the most notifications (74 notifications for TAVI and 48 for BVS). At least one recall was identified for seven technologies in Germany and for six additional technologies internationally.

\section{Characteristics of the body of evidence}

The composition of the body of evidence per technology is shown in figure $2 \mathrm{~A}$. For almost all technologies the bulk of the evidence consists of case series and other non-comparative studies; these designs make up more than half of all identified publications across technologies (943/1840) (figure 2B). 
Only 213/1840 (12\%) of included publications report results from 130 individual RCTs. The number of RCTs with at least one publication per technology varies from one (e.g. PECLA/iLA) to 19 (drug-coated balloon catheter in coronary vessels - DCB-CV). No RCT was identified for six out of 25 technologies. Most identified RCTs show high RoB. Only for five technologies, at least one RCT with low RoB was identified (additional file 1 appendix 9 figure 9.1).

The number of systematic reviews and HTA reports ranges from zero (e.g. flow-diverter (Hemodynamically effective implant for endovascular treatment of peripheral aneurysms) in upper leg vessels - FD-ULV) to 37 (TAVI). Interestingly, the number of systematic reviews is higher than the number of RCTs for most technologies. For some technologies, there were several systematic reviews analysing the same group of RCTs (e.g. intracranial endovascular mechanical thrombectomy - MT). More details on study characteristics can be found in additional file 1 appendix 9 .

\section{Development of body of evidence over time}

In the first years of documented utilization, the number of available publications is low for almost every technology in the sample. Results from non-comparative study designs (LoE 4) usually dominate the picture. Despite the increasing share of evidence from LoE 1-3 on all publications over the course of the observation period (additional file 1 appendix 10 figure 10.1), the number of such publications remains beneath that of Level 4 for the majority of technologies (additional file 1 appendix 10 figure 10.2). A substantial lag (up to 9 years) can be observed between the first year of utilization and the publication of first results from RCTs for several technologies (additional file 1 appendix 9 figure 9.1).

\section{Results of the evidence on innovative technologies}

Figure 3 shows the proportion of publications with positive, negative, neutral, and inconclusive results per technology. It is noticeable that for some technologies, the share of inconclusive publications is relatively high; in particular case series and other single-arm studies did not always fall into positive, negative, or neutral category due to ambiguity in the conclusions (e.g. better efficacy but poorer safety) (additional file 1 appendix 11 figure 11.1). A detailed distribution of publications by results category, LoE and technology is shown in additional file 1 appendix 11 figures 11.2 and 11.3(A-C). Negative results tended to be observed more frequently among studies with a comparison group. On the contrary, LoE 4 studies tended to conclude positively more often.

\section{Utilization of innovative technologies}

The observed utilization of the technologies in the study sample, measured by billed number of cases per year, is shown in figure 4 . The maximum number of cases per year ranges from $138(2014$, selfexpanding bare metal stents in coronary vessels - SE-BMS) to 42203 (2017, anticoagulation with citrate during dialysis $-A C D$ ). The number of years with reimbursed inpatient cases identified through specific procedure codes in the observation period ranged from four (SE-BMS) to 13 (Cardiac event recorder after ablative measures for atrial fibrillation / atrial tachycardia - ER-ABL), with a median of 10 (2008). 


\section{Funding of innovative technologies}

As shown in figure 4, the beginning of utilization is linked to the permission to negotiate extra-budgetary payments with health insurance funds for most technologies. Exceptions are ER-ABL, F-TUR and mitral valve annuloplasty with clamp (MVAC), for which utilization starts earlier. For most technologies, the end of the permission to negotiate extra-budgetary payments coincides with the beginning of the next stage of reimbursement. At the end of the observation period, negotiable or fixed additional file 1 payments applied for 12 out of 25 technologies, while seven were included in a DRG. A change of reimbursement occurred after one to seven years. For the five remaining technologies (endo-aortic balloon occlusion with extracorporeal circulation - EABO, FD-ULV, bioactive coils for intracranial aneurysm therapy - IABC, MVAC, SE-BMS), funding did not change over time.

\section{Relationship between utilization and other factors}

Table 1 Results of multilevel estimation of the relationship between the available body of evidence and utilization

Number of hospital cases

Predictors

Fixed Effects

(Intercept)

Results of available body of evidence

Random Effects

$$
\sigma^{2}
$$

Yoo technology

11621363.15

10344.00

Y11 technology. Results of available body of evidence

0.77

$\rho_{01 \text { technology }}$

ICC

0.95

$\mathrm{N}_{\text {technology }}$

22

Observations

217

Marginal $\mathrm{R}^{2}$ / Conditional $\mathrm{R}^{2}$

$0.150 / 0.955$

Source: Created by the authors in RStudio (Version 1.4.1717) using Ime4 package
The multilevel regression showed a statistically significant relationship between the direction of evidence and the direction of utilization (table 1). The different orders of magnitude in utilization across technologies, resulting primarily from the varying prevalence of the underlying conditions, 
may explain the very high variance. The high intra-class correlation (ICC) confirms the appropriateness of the clustered approach $(28,30)$.

Figure 4 illustrates the agreement between observed annual utilization and predicted utilization based on evidence (fitted values) per technology. For most technologies, increasing utilization goes along with positive evidence (e.g. TAVI) or decreasing utilization goes along with negative evidence (e.g. BVS). In contrast, predicted values are not in line with observed values for seven technologies (e.g. Lung volume reduction by insertion of coils - LVRC); this implies that factors other than evidence had a stronger influence on utilization. The results of the analysis are additionally presented in a heatmap in the additional file 1 appendix 13, which maps the direction of results of the body of evidence and the change in direction of utilization compared to the previous year.

As can be seen in figure 4, no consistent patterns emerge regarding the relationship between trends in utilization and funding changes.

The impact of safety notifications and recalls is difficult to analyse, particularly as multiple products are available for most technologies in the sample. For technologies with at most two identified products and one identified recall (excimer laser extraction of pacemaker and defibrillator electrodes - EL-P/ICD (31) in 2012, dialysis with high cut-off dialysis membrane - HCO (32) in 2011, PECLA/iLA (33) in 2006), no relationship is observable. In the case of BVS, safety warnings restricting use to certain vessels (34) and selected facilities participating in clinical registries (35) negative evidence followed by a decline in utilization.

\section{Discussion}

This work evaluated the relationship between the utilization of 25 technologies for different anatomical systems in German inpatient care and available clinical evidence, as well as changes in funding and safety information.

The number of included publications per technology ranged from two to 498, with case-series and other non-comparative designs constituting the bulk of the evidence body. Although this reflects the interest of clinicians in sharing their experience with a certain technology in a real-world setting, such studies do not provide an adequate foundation to conclude on a technology's comparative value. For seven of the 25 technologies, a maximum of one publication from the two highest evidence levels (systematic reviews of RCTs or individual RCTs) was identified despite high utilization numbers. In fact, for most included technologies there were few RCTs, predominantly with high RoB. A high volume of publications does not necessarily predicate the robustness of the evidence body on the benefit of a technology. Similarly, the availability of multiple systematic reviews of comparative studies (LoE 1a/2a) for the same technology does not necessarily result in information gain. For example, several systematic reviews/meta-analyses on stent retrievers for mechanical thrombectomy in acute stroke were identified in this work, published within two years and combining the same six RCTs. What is more, findings in systematic reviews are only as robust as the studies included in the review allow. 
The trend towards higher LoE over time was not always observable. For several technologies, a robust body of evidence (e.g. at least one RCT with low risk of bias) did not materialise for several years or even until the end of the observation period. Across technologies, the number of years and the number of patients treated before adequate scientific evidence became available varied. The type of FDA approval, which is tied to post-market evidence generation requirements, and could thus have influenced the number and type of available studies $(36,37)$, was not investigated further. However, it seems like the lack of mandatory benefit assessment before reimbursement potentially exposed patients to undue harm (including lack of benefit) and the health system to inefficient spending. Other European countries, such as France (38) and the UK (39), have established pathways of comparative effectiveness assessment of new technologies prior to reimbursement of innovative technologies. An evaluation pathway was established for certain high-risk innovative technologies in German inpatient care in 2016 (§137h SGB V), mandating hospitals seeking to negotiate extrabudgetary payments for the first time to provide the FJC with available evidence on effectiveness. This did not apply to any of the technologies in the sample.

A relationship between evidence and utilization could be shown for some technologies, but not all. Up to a point, this was to be expected, as there are many factors that influence the adoption of new technologies in healthcare organisations that could not be accounted for in the regression model. The available number of alternative technologies, operator experience, user-friendly operation, organizational culture, individual beliefs and preferences of operators and patient demand $(40,41)$ can play a role in the diffusion process. It is also thinkable that high initial acquisition costs lead to the continued use of technology despite the availability of better alternatives. Finally, even if a technology is reimbursable and has a positive evidence profile, insurers may not be willing to agree to extra-budgetary or supplementary payments that cover all costs.

The relationship between utilization and funding, as well as the relationship between utilization and safety notifications were explored in a qualitative manner, without clear results. However, this does not fully exclude the possibility that such relationships existed for any of the technologies. This study was not designed to predict what utilization might have looked like if funding had not changed over time from the most insecure (extra-budgetary payments) to more secure types of funding (e.g. adequate depiction in a DRG). For at least one technology, safety notices and restrictions could have strengthened the effect of clinical evidence, but this relationship also proved impossible to evaluate fully with this study design.

To ensure quality of care, it is important that reimbursed technologies are safe and effective. The first step towards achieving this is to have regulatory processes in place that only allow such medical devices to enter the market. The changes introduced by the MDR, which took effect in May $2021(5,8)$, could reduce the number of years of utilization without robust evidence in German inpatient care and elsewhere in Europe (and the time lag between CE-certification and FDA approval (42)) but this will also depend on how the regulation is implemented.

The second step is to assess the comparative effectiveness or even cost-effectiveness of new technologies prior to reimbursement. Every health system needs to balance timely access with certainty 
on the safety and effectiveness of an innovation, while distributing limited resources wisely. For new technologies that show promise but are not supported by adequate evidence yet, coverage with evidence development (CED) may provide a solution. CED is used by several European countries, such as Belgium, England, France, the Netherlands, Spain, and Switzerland (43), and has also been introduced in Germany (44). It is important to design such programs carefully, particularly as public institutions are often not experienced in planning and conducting clinical trials, which can lead to delays and - depending on program set-up - challenges with access or inefficiencies (43). Further, CED has the potential to support innovation from small and medium size manufacturers of medical devices, who may not be able to afford large clinical trials otherwise.

\section{Limitations}

This work has several limitations. Although the sample of included technologies was selected in a systematic approach (22), no claim to representativeness can be made for all new technologies. Thus, these results remain indicative; however, this does not detract from their relevance given the dearth of related previous research.

The calculation of utilization is based on procedure documentation. The quality of the coding depends both on the experience of the coder and the extent to which the codes used only capture the distinct technologies in the sample (as opposed to also capturing related technologies for which no unique codes existed yet). Furthermore, the procedure classification system is subject to regular changes, and codes may change over time as the classification becomes more detailed. This could have resulted in a distortion of observed utilization for some technologies (e.g. F-TUR).

Due to the rapid review methodology adopted to identify evidence, it is possible that either not all relevant citations were identified, or potentially relevant studies were excluded, e.g. through exclusion of languages other than German or English, and non-availability of full texts. Additional sources for clinical guidelines and HTA reports were chosen from the perspective of the German context; thus, these results are not exhaustive.

For feasibility reasons, results per publication were categorized based solely on the conclusions of the authors. This means that the consistency of these conclusions with outcomes reported in the publication results section was not investigated further and the potential influence of spin (45) has not been accounted for. Furthermore, studies with negative results are overall less likely to be published (46) - this study did not account for publication bias. Finally, different authors were involved in the selection and categorization of evidence per technology. Despite frequent meetings and consensus discussions with the full author team investigator bias cannot be excluded.

The aggregated variable representing the body of evidence in the multilevel regression model has the advantage of considering the entire body of evidence available up to the time point of utilization and avoiding distortions, for instance because of a single negative study. However, the disadvantage is that the impact of one single, crucial study, can be underestimated. Furthermore, the consideration and 
weighting of different study designs reflects a choice based on evidence hierarchies and could be subject to discussion. Finally, other observable (e.g. funding, safety warnings, disease incidence) and unobservable factors were not incorporated into the model.

\section{Conclusions}

This is the first study investigating the relationship between evidence and utilization for a sample of 25 new medical technologies in German inpatient care in a descriptive and empirical manner. The body of clinical evidence per technology often consisted mainly of non-comparative studies; its robustness increased over time for many but not all technologies. A relationship between evidence and utilization could be shown for some, albeit not all, technologies. The influence of funding and safety notices requires further investigation. These results reveal that a re-evaluation of market approval standards and HTA pathways might be warranted.

\section{List Of Abbreviations}

ACD - Anticoagulation with citrate during dialysis; ACT - Adjustable continence therapy; BVS Bioresorbable Vascular Scaffold in coronary vessels; CED - coverage with evidence development; DCB-AV - Drug-coated balloon catheter in abdominal vessels; DCB-CV - Drug-coated balloon catheter in coronary vessels; DCB-IV - Drug-coated balloon catheter in intracranial vessels; DCB-LLV - Drug-coated balloon catheter in lower leg vessels; DCB-ULV - Drug-coated balloon catheter in upper leg vessels; DEB-TACE Drug-eluting beads for transarterial chemoembolization; DES-LLV - Implantation of a drug-eluting stent in lower leg vessels; DES-ULV - Implantation of a drug-eluting stent in upper leg vessels; DRG - DiagnosisRelated Groups; EABO - Endoaortic balloon occlusion with extracorporeal circulation; EL-P/ ICD - Excimer laser extraction of pacemaker and defibrillator electrodes; ER-ABL - Cardiac event recorder after ablative measures for atrial fibrillation / atrial tachycardia; EU - European Union, FDA - Food and Drug Administration; FD-ULV - Flow-diverter (Hemodynamically effective implant for endovascular treatment of peripheral aneurysms) in upper leg vessels; FJC - Federal Joint Committee (Gemeinsamer Bundesausschuss); F-TUR - Fluorescence-assisted transurethral resection; HCO - Dialysis with high cut-off dialysis membrane; HTA - health technology assessment; IABC - Bioactive coils for intracranial aneurysm therapy; InEK - Institute for the Hospital Remuneration System (Institut fuer das Entgeltsystem im Krankenhaus); IQWiG - Institute for Quality and Effıciency in Health Care (Institut für Qualität und Wirtschaftlichkeit im Gesundheitswesen); LVRC - Lung volume reduction by insertion of coils; LoE - level of evidence, MDR - Medical Device Regulation, MDS - National Association of Health Insurance Funds (Medizinischer Dienst des Spitzenverbandes Bund der Krankenkassen e.V.); MT - Intracranial endovascular mechanical thrombectomy; MVAC - Mitral valve annuloplasty with clamp; NUB - New Diagnostic and Treatment Methods (Neue Untersuchungs- und Behandlungsmethode); OPS - German Operations and Procedures Classification (Operationen- und Prozedurenschluessel); PECLA/ iLA Pumpless Extracorporeal Lung Assist/ Interventional Lung Assist; pVAD - Percutaneous ventricular assist device (Micro-axial blood pump); RCT - Randomised controlled clinical trial; RoB - Risk of bias; SE-BMS - 
Self-expanding bare metal stents in coronary vessels; SGB V - German Social Code Book V; TAVI Transcatheter aortic valve implantation; US - United States

\section{Declarations}

\section{Ethics approval and consent to participate}

Not applicable.

\section{Consent for publication}

Not applicable.

\section{Availability of data and materials}

The datasets used and/or analysed during the current study are available from the corresponding author on reasonable request.

\section{Competing interests}

The authors declare that they have no competing interests. SaF is employed by the Federal Joint Committee at the time of submission, but worked at the Department of Health Care Management during the time of her contribution to this work.

\section{Funding}

The research underlying this publication was partially supported by a grant from the German National Association of Statutory Health Insurance Funds the umbrella organization of social health insurers in Germany. The broad research area for the research grant was provided, but the development of the methods, the research activity, the analysis and interpretation were performed by the authors independently. This article includes additional analyses, which were made possible by the Berlin Centre for Health Economics Research (BerlinHECOR), funded by the Federal Ministry for Education and Research. The manuscript was prepared solely based on the initiative of the author team. Four of the authors (SuF, MB, RB, CH) are members of the BerlinHECOR group at the Technische Universität Berlin. The Department of Health Care Management receives research funding from a multitude of public or nonprofit institutions, which are listed on the Department's website. Open Access funding enabled and organized by Projekt DEAL.

\section{Authors' contributions}

$\mathrm{HeE}$, SuF, MD, HaE, SaF, HaE, HL, TR, RB, CH and DP all contributed to the conceptualization of the overall project. HeE, SuF, MD, HaE, SaF, HaE, HL, TR, CH and DP were involved in the identification, selection and analysis of published evidence. The overall approach in this article was conceptualized by HeE, DP and 
$\mathrm{CH}$. The empirical analysis was conceptualised and carried out by HeE. HeE wrote the manuscript with contributions from DP and $\mathrm{CH}$. All authors read, commented, and approved the final manuscript.

\section{Acknowledgements}

We thank Helena Clara Aurich, Anne Charlotte Bunge, Alessandro Campione, Anna Irshad, Fabian Krakowski, Hauke Langhoff, Wiktor Łuczak, Yasmina Mansour, Carmen Cecilia Schroll, Fabian Schütte, Nathan Alexander Shuftan, Maximilian Teitscheid, and Iris Thielemann for their support.

\section{Author information}

Dimitra Panteli and Cornelia Henschke shared senior authorship.

\section{References}

1. Howard JJ. Balancing innovation and medical device regulation: the case of modern metal-on-metal hip replacements. Med Devices (Auckl) 2016; 9:267-75.

2. Heneghan C, Thompson M, Billingsley M, Cohen D. Medical-device recalls in the UK and the deviceregulation process: retrospective review of safety notices and alerts. BMJ Open 2011; 1(1):e000155.

3. Rägo L, Santoso B. Chaper 6: Drug Regulation: History, Present and Future. In: van Boxtel CJ, Santoso B, Edwards IR, editors. Drug benefits and risks: International textbook of clinical pharmacology. Rev. 2. ed. Amsterdam: IOS Press; 2008. p. 65-77 [cited 2021 Sep 7]. Available from: URL:

https://www.who.int/medicines/technical_briefing/tbs/Drug_Regulation_History_Present_Future.pdf.

4. Directive 2007/47/EC of the European Parliament and of the Council of 5 September 2007 amending Council Directive 90/385/EEC on the approximation of the laws of the Member States relating to active implantable medical devices, Council Directive 93/42/EEC concerning medical devices and Directive 98/8/EC concerning the placing of biocidal products on the market (Text with EEA relevance) [L 247/21]. Official Journal of the European Union 2007 Sep 21 [cited 2021 Sep 24]:2155. Available from: URL: https://eur-lex.europa.eu/legal-content/EN/TXT/? uri=celex\%3A32007L0047.

5. Regulation (EU) 2017/745 of the European Parliament and of the Council of 5 April 2017 on medical devices, amending Directive 2001/83/EC, Regulation (EC) No 178/2002 and Regulation (EC) No 1223/2009 and repealing Council Directives 90/385/EEC and 93/42/EEC (Text with EEA relevance.) [L 117/1]. Official Journal of the European Union 2017 May 5:1-175. Available from: URL: https://eur-lex.europa.eu/legal-content/EN/TXT/?uri=celex\%3A32017R0745.

6. Consolidated text: Council Directive 93/42/EEC of 14 June 1993 concerning medical devices; 2007 Oct 11 [cited 2021 Sep 24]. Available from: URL: https://eur-lex.europa.eu/legalcontent/EN/TXT/PDF/?uri=CELEX:01993L0042-20071011\&from=EN. 
7. Consolidated text: Council Directive of 20 June 1990 on the approximation of the laws of the Member States relating to active implantable medical devices (90/385/EEC); 2007 Oct 11 [cited 2021 Sep 24]. Available from: URL: https://eur-lex.europa.eu/legal-content/EN/TXT/PDF/? uri=CELEX:01990L0385-20071011\&from=EN.

8. Fraser AG, Byrne RA, Kautzner J, Butchart EG, Szymański P, Leggeri I et al. Implementing the new European Regulations on medical devices-clinical responsibilities for evidence-based practice: a report from the Regulatory Affairs Committee of the European Society of Cardiology. Eur Heart $J$ 2020; 41(27):2589-96.

9. Title 21: Food and Drugs/ PART 860-MEDICAL DEVICE CLASSIFICATION PROCEDURES/ Subpart A -General/ §860.7 Determination of safety and effectiveness: 43 FR 32993, 53 FR 11253, 73 FR 49942; 2012. Available from: URL: https://www.govinfo.gov/content/pkg/CFR-2012-title21vol8/pdf/CFR-2012-title21-vol8-sec860-7.pdf.

10. Sastry A. Overview of the US FDA medical device approval process. Curr Cardiol Rep 2014; 16(6):494.

11. Monsein LH. Primer on medical device regulation. Part I. History and background. Radiology 1997; 205(1):1-9.

12. Panteli D, Eckhardt $H$, Nolting A, Busse R, Kulig M. From market access to patient access: overview of evidence-based approaches for the reimbursement and pricing of pharmaceuticals in 36 European countries. Health Res Policy Syst 2015; 13(1):39.

13. Fuchs S, Olberg B, Panteli D, Busse R. HEALTH TECHNOLOGY ASSESSMENT OF MEDICAL DEVICES IN EUROPE: PROCESSES, PRACTICES, AND METHODS. International Journal of Technology Assessment in Health Care 2016; 32(4):246-55.

14. Beck A, Retèl VP, Bhairosing PA, van den Brekel M, van Harten WH. Barriers and facilitators of patient access to medical devices in Europe: A systematic literature review. Health Policy 2019; 123(12):1185-98.

15. Sorenson C, Drummond M, Burns LR. Evolving reimbursement and pricing policies for devices in Europe and the United States should encourage greater value. Health Affairs 2013; 32(4):788-96.

16. Scheller-Kreinsen D, Quentin W, Busse R. DRG-based hospital payment systems and technological innovation in 12 European countries. Value Health 2011; 14(8):1166-72.

17. Henschke C, Bäumler M, Weid S, Gaskins M, Busse R. Extrabudgetary ('NUB') payments: A gateway for introducing new medical devices into the German inpatient reimbursement system? Journal of Management \& Marketing in Healthcare 2010; 3(2):119-33.

18. Ex P, Henschke $C$. Changing payment instruments and the utilisation of new medical technologies. Eur J Health Econ 2019; 20(7):1029-39.

19. Akintoye E, Ando T, Sandio A, Adegbala O, Salih M, Zubairu J et al. Aortic Valve Replacement for Severe Aortic Stenosis Before and During the Era of Transcatheter Aortic Valve Implantation. The American journal of cardiology 2020; 126:73-81.

20. Raftery J, Hanney S, Greenhalgh T, Glover M, Blatch-Jones A. Models and applications for measuring the impact of health research: update of a systematic review for the Health Technology Assessment 
programme. Health Technol Assess 2016; 20(76):1-254.

21. Hailey D. A systematic review of publications that have reported the influence of health technology assessment.

22. Dreger M, Eckhardt H, Felgner S, Errmann H, Lantzsch H, Rombey T et al. Implementation of Innovative Medical Technologies In German Inpatient Care: Patterns of Utilization And Evidence Development 2021.

23. Bramer WM, Giustini D, Jonge GB de, Holland L, Bekhuis T. De-duplication of database search results for systematic reviews in EndNote. J Med Libr Assoc 2016; 104(3):240-3.

24. Gemeinsamer Bundesausschuss. Verfahrensordnung (VerfO) des Gemeinsamen Bundesausschusses in der Version vom 06.03.2019: in der Fassung vom 18. Dezember 2008 veröffentlicht im Bundesanzeiger Nr. 84a (Beilage) vom 10. Juni 2009 in Kraft getreten am 1. April 2009 zuletzt geändert am 16. August 2018 veröffentlicht im Bundesanzeiger BAnz AT 05.03.2019 B2 in Kraft getreten am 6. März 2019; 2019 Mar 15 [cited 2021 Sep 24]. Available from: URL: https://www.g-ba.de/downloads/62-492-1777/VerfO_2018-08-16_iK-2019-03-06.pdf.

25. Garritty C, Gartlehner G, Nussbaumer-Streit B, King VJ, Hamel C, Kamel C et al. Cochrane Rapid Reviews Methods Group offers evidence-informed guidance to conduct rapid reviews. J Clin Epidemiol 2021; 130:13-22.

26. Moher D, Liberati A, Tetzlaff J, Altman DG. Preferred reporting items for systematic reviews and meta-analyses: the PRISMA statement. PLoS Med 2009; 6(7):e1000097.

27. Jones K, Duncan C. Modelling Context and Heterogeneity: Applying Multilevel Models. In: Scarbrough $\mathrm{E}$, Tanenbaum E, editors. Research strategies in the social sciences: A guide to new approaches. Oxford: Oxford Univ. Press; 1998. p. 95-124.

28. Hox JJ. Multilevel analysis: Techniques and applications. 2. ed. New York: Routledge Taylor \& Francis; 2010. (Quantitative methodology series).

29. Balas EA, Chapman WW. Road Map For Diffusion Of Innovation In Health Care. Health Affairs 2018; 37(2):198-204.

30. Chen G, Taylor PA, Haller SP, Kircanski K, Stoddard J, Pine DS et al. Intraclass correlation: Improved modeling approaches and applications for neuroimaging. Hum. Brain Mapp. 2018; 39(3):1187-206.

31. Bundesinstitut für Arzneimittel und Medizinprodukte. Chargenrückruf der 12 Fr SLS II Laser Schleusen, Spectranetics Corporation: 12Fr SLS® II Rückrufbenachrichtigung; 2012. Available from: URL: https://www.bfarm.de/SharedDocs/Kundeninfos/DE/07/2012/01749-12_kundeninfo_de.pdf? _blob=publicationFile.

32. Bundesinstitut für Arzneimittel und Medizinprodukte. Chargenrückruf Theralite High Cut-OffDialysator, Gambro Dialysatoren GmbH: Wichtiger Sicherheitshinweis (Field Safety Notice); 2011 [cited 2021 Aug 25]. Available from: URL: https://www.bfarm.de/SharedDocs/Kundeninfos/DE/07/2011/03195-11_kundeninfo_de.pdf? _blob=publicationFile. 
33. Bundesinstitut für Arzneimittel und Medizinprodukte. Rückruf des Produktes iLA interventional Lung Assist Membrane Ventilator von NovaLung; 2006. Available from: URL:

https://www.bfarm.de/SharedDocs/Kundeninfos/DE/12/2006/02630-06_kundeninfo_de.pdf? _blob=publicationFile.

34. Abbott Vascular. DRINGENDE SICHERHEITSINFORMATION / MASSNAHMENEMPFEHLUNG FÜR ÄRZTE: Globale Harmonisierung der Absorb und Absorb GT1 Indikation [27. July 2016]:

Bundesinstitut für Arzneimittel und Medizinprodukte; 2016 [cited 2019 Nov 29]. Available from: URL: https://www.bfarm.de/SharedDocs/Kundeninfos/DE/11/2016/09125-15_kundeninfo_de.pdf? _blob=publicationFile\&v $=3$.

35. Abbott Vascular. DRINGENDE SICHERHEITSINFORMATION / MASSNAHMENEMPFEHLUNG FÜR ÄRZTE: Bioresorbierbare vaskuläre Gerüstsysteme (BVS) Absorb ${ }^{\text {TM }}$ und AbsorbGT1 ${ }^{\text {TM }}$ [31 März 2017]: Bundesinstitut für Arzneimittel und Medizinprodukte; 2017 [cited 2019 Nov 29]. Available from: URL: https://www.bfarm.de/SharedDocs/Kundeninfos/DE/11/2017/03018-17_Kundeninfo_de.pdf? _blob=publicationFile\&v $=1$.

36. Zuckerman D, Brown P, Das A. Lack of publicly available scientific evidence on the safety and effectiveness of implanted medical devices. JAMA Intern Med 2014; 174(11):1781-7.

37. Rathi VK, Krumholz HM, Masoudi FA, Ross JS. Characteristics of Clinical Studies Conducted Over the Total Product Life Cycle of High-Risk Therapeutic Medical Devices Receiving FDA Premarket Approval in 2010 and 2011. JAMA 2015; 314(6):604-12.

38. Chevreul K, Berg Brigham K, Durand-Zaleski I, Hernández-Quevedo C. France: Health system review.; 2015. (Health Systems in Transition17 (3)).

39. Cowles E, Marsden G, Cole A, Devlin N. A Review of NICE Methods and Processes Across Health Technology Assessment Programmes: Why the Differences and What is the Impact? Appl Health Econ Health Policy 2017; 15(4):469-77.

40. Wisdom JP, Chor KHB, Hoagwood KE, Horwitz SM. Innovation adoption: a review of theories and constructs. Adm Policy Ment Health 2014; 41(4):480-502.

41. Greenhalgh T, ROBERT G, MACFARLANE F, BATE P, KYRIAKIDOU O. Diffusion of innovations in service organizations: systematic review and recommendations. Milbank Quarterly 2004; 82(4):581-629.

42. Wild C, Erdös J, Zechmeister I. Contrasting clinical evidence for market authorisation of cardiovascular devices in Europe and the USA: a systematic analysis of 10 devices based on Austrian prereimbursement assessments. BMC Cardiovascular Disorders 2014; 14:154.

43. Federici C, Reckers-Droog V, Ciani O, Dams F, Grigore B, Kaló Z et al. Coverage with evidence development schemes for medical devices in Europe: characteristics and challenges. Eur $\mathrm{J}$ Health Econ 2021.

44. Felgner S, Ex P, Henschke C. Physicians' Decision Making on Adoption of New Technologies and Role of Coverage with Evidence Development: A Qualitative Study. Value Health 2018; 21(9):1069-76.

45. Chiu K, Grundy Q, Bero L. 'Spin' in published biomedical literature: A methodological systematic review. PLoS Biol 2017; 15(9):e2002173. 
46. Panteli D, Nolting A, Eckhardt $\mathrm{H}$, Kulig M, Busse R. Published and unpublished evidence in coverage decision-making for pharmaceuticals in Europe: existing approaches and way forward. Health Res Policy Syst 2016; 14:6.

\section{Figures}

\begin{tabular}{|c|c|}
\hline Result category & Rationale of categorisation of key messages in authors' conclusions \\
\hline Positive & $\begin{array}{l}\text { The authors' conclusions are consistently positive (regarding efficacy AND safety, AND across } \\
\text { patient groups). } \\
\text { When a neutral (e.g., "equally safe") and a positive (e.g., "effective") statement were } \\
\text { combined, this publication was considered positive. }\end{array}$ \\
\hline Negative & $\begin{array}{l}\text { The authors' conclusions are consistently negative (regarding efficacy AND safety, and across } \\
\text { patient groups). } \\
\text { When a neutral (e.g., "equally safe") and a negative (e.g., "less effective") statement were } \\
\text { combined, this publication was classified as negative. }\end{array}$ \\
\hline Neutral & The authors conclude that there is no difference between intervention and comparator. \\
\hline Inconclusive & $\begin{array}{l}\text { The authors conclude that no definite statement can be made, e.g., because } \\
\text { - there is better efficacy but poorer safety, } \\
\text { - the result is not generalizable for all patients (recommended for some, but not for } \\
\text { all), } \\
\text { - the authors do not make a statement in the conclusion, neither explicitly ("no } \\
\text { statement is possible") nor implicitly (by using "could", "maybe", "possibly"), } \\
\text { - studies report only surrogate parameters and no conclusion on patient benefit is } \\
\text { possible. }\end{array}$ \\
\hline
\end{tabular}

\section{Figure 1}

Rationale of categorisation of key messages in authors' conclusions Source: Created by the authors 
A

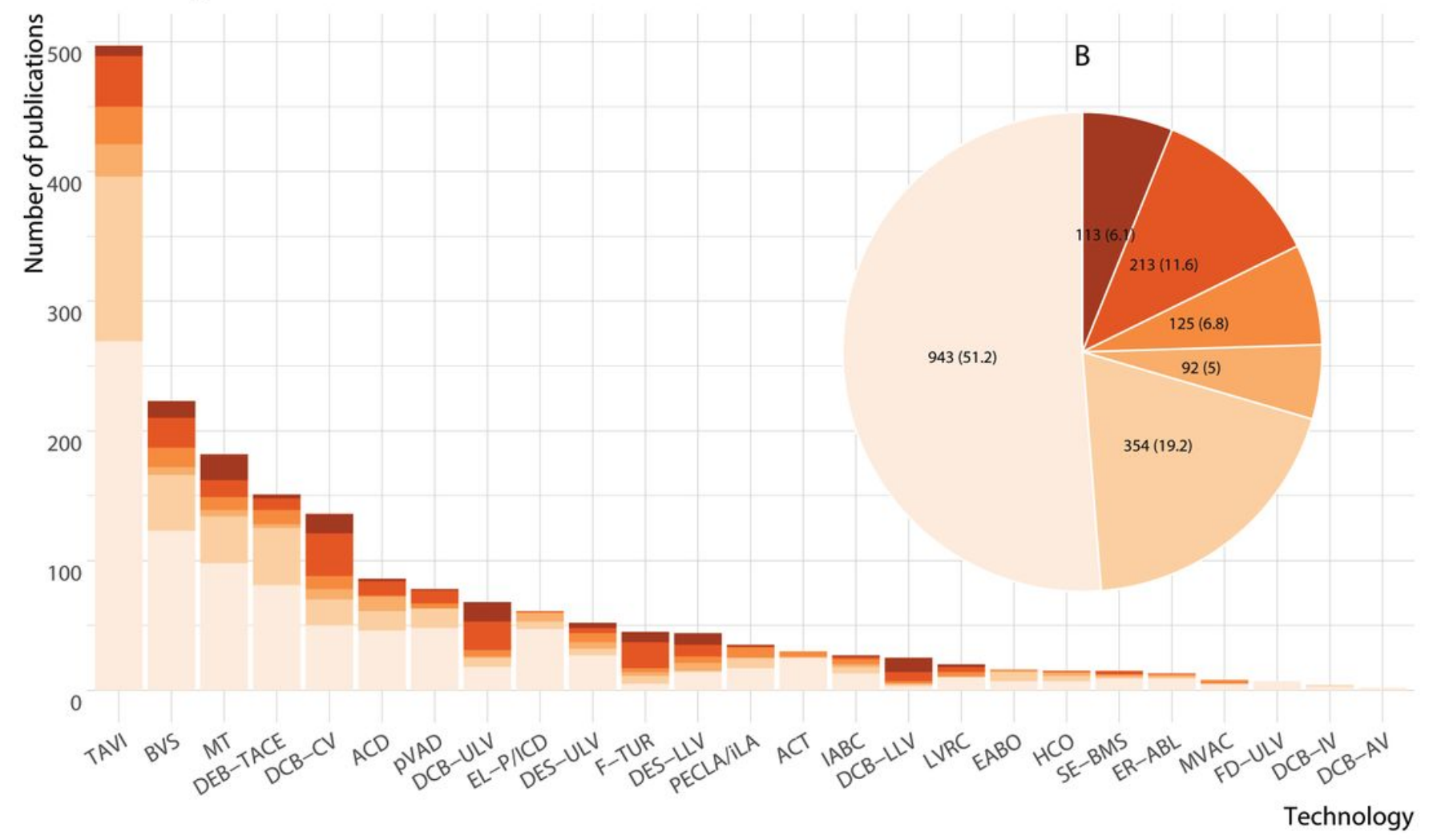

\section{Figure 2}

Number of publications (A) by level of evidence (LoE) and technology, (B) by LoE [n(\%)]* Source: Created by the authors; Notes: *Number of publications summed over all technologies per LoE; Abbreviations: ACD - Anticoagulation with citrate during dialysis; ACT - Adjustable continence therapy; BVS -

Bioresorbable Vascular Scaffold in coronary vessels; DCB-AV - Drug-coated balloon catheter in abdominal vessels; DCB-CV - Drug-coated balloon catheter in coronary vessels; DCB-IV - Drug-coated balloon catheter in intracranial vessels; DCB-LLV - Drug-coated balloon catheter in lower leg vessels; DCB-ULV - Drugcoated balloon catheter in upper leg vessels; DEB-TACE - Drug-eluting beads for transarterial chemoembolization; DES-LLV - Implantation of a drug-eluting stent in lower leg vessels; DES-ULV Implantation of a drug-eluting stent in upper leg vessels; EABO - Endoaortic balloon occlusion with extracorporeal circulation; EL-P/ ICD - Excimer laser extraction of pacemaker and defibrillator electrodes; ER-ABL - Cardiac event recorder after ablative measures for atrial fibrillation / atrial tachycardia; FD-ULV Flow-diverter (Hemodynamically effective implant for endovascular treatment of peripheral aneurysms) in upper leg vessels; F-TUR - Fluorescence-assisted transurethral resection; HCO - Dialysis with high cutoff dialysis membrane; IABC - Bioactive coils for intracranial aneurysm therapy; LVRC - Lung volume reduction by insertion of coils; MT - Intracranial endovascular mechanical thrombectomy; MVAC - Mitral valve annuloplasty with clamp; PECLA/ iLA - Pumpless Extracorporeal Lung Assist/ Interventional Lung Assist; pVAD - Percutaneous ventricular assist device (Micro-axial blood pump); SE-BMS - Self-expanding bare metal stents in coronary vessels; TAVI - Transcatheter aortic valve implantation 


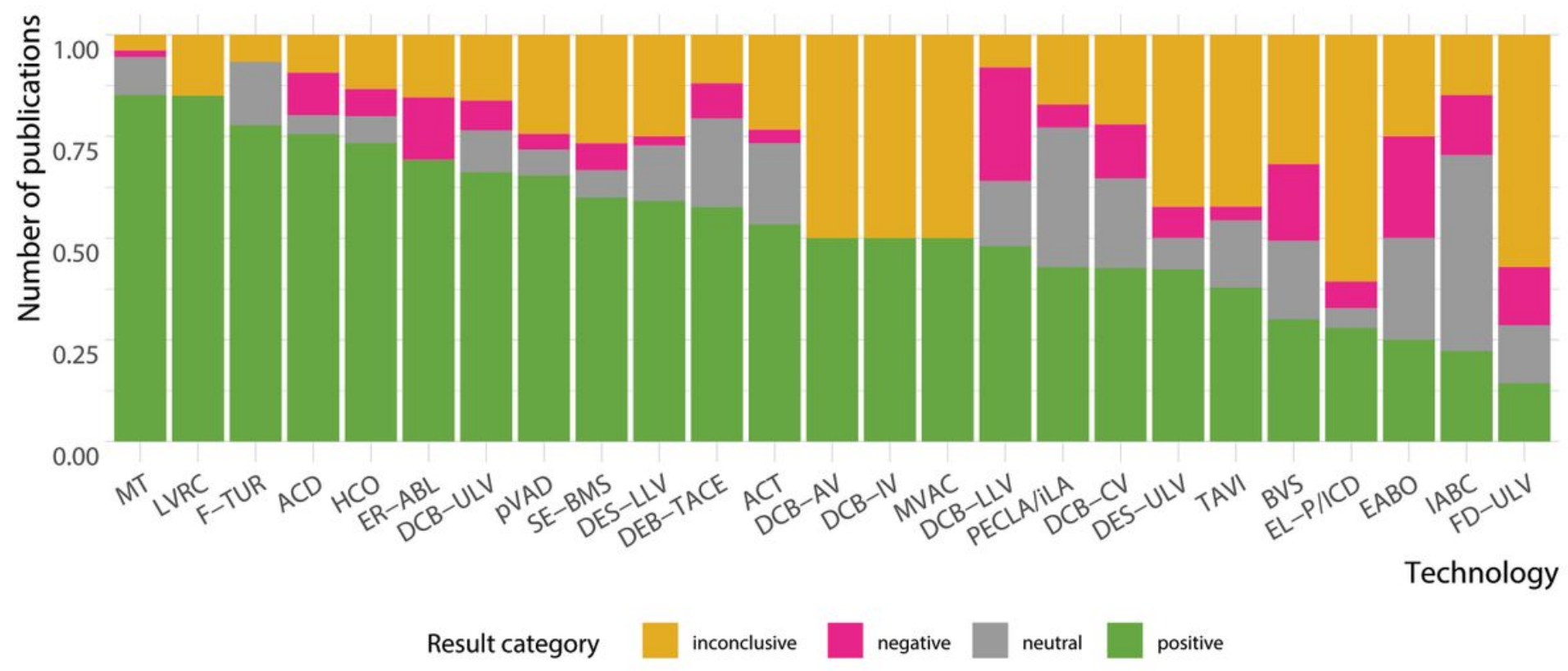

\section{Figure 3}

Conclusions of publications (LoE 1-4) per technology Source: Created by the authors; Notes: The figure shows proportion of publications by results category on all identified publications per technology; Abbreviations: ACD - Anticoagulation with citrate during dialysis; ACT - Adjustable continence therapy; BVS - Bioresorbable Vascular Scaffold in coronary vessels; DCB-AV - Drug-coated balloon catheter in abdominal vessels; DCB-CV - Drug-coated balloon catheter in coronary vessels; DCB-IV - Drug-coated balloon catheter in intracranial vessels; DCB-LLV - Drug-coated balloon catheter in lower leg vessels; DCBULV - Drug-coated balloon catheter in upper leg vessels; DEB-TACE - Drug-eluting beads for transarterial chemoembolization; DES-LLV - Implantation of a drug-eluting stent in lower leg vessels; DES-ULV Implantation of a drug-eluting stent in upper leg vessels; EABO - Endoaortic balloon occlusion with extracorporeal circulation; EL-P/ ICD - Excimer laser extraction of pacemaker and defibrillator electrodes; ER-ABL - Cardiac event recorder after ablative measures for atrial fibrillation / atrial tachycardia; FD-ULV Flow-diverter (Hemodynamically effective implant for endovascular treatment of peripheral aneurysms) in upper leg vessels; F-TUR - Fluorescence-assisted transurethral resection; HCO - Dialysis with high cutoff dialysis membrane; IABC - Bioactive coils for intracranial aneurysm therapy; LVRC - Lung volume reduction by insertion of coils; MT - Intracranial endovascular mechanical thrombectomy; MVAC - Mitral valve annuloplasty with clamp; PECLA/ iLA - Pumpless Extracorporeal Lung Assist/ Interventional Lung Assist; pVAD - Percutaneous ventricular assist device (Micro-axial blood pump); SE-BMS - Self-expanding bare metal stents in coronary vessels; TAVI - Transcatheter aortic valve implantation 

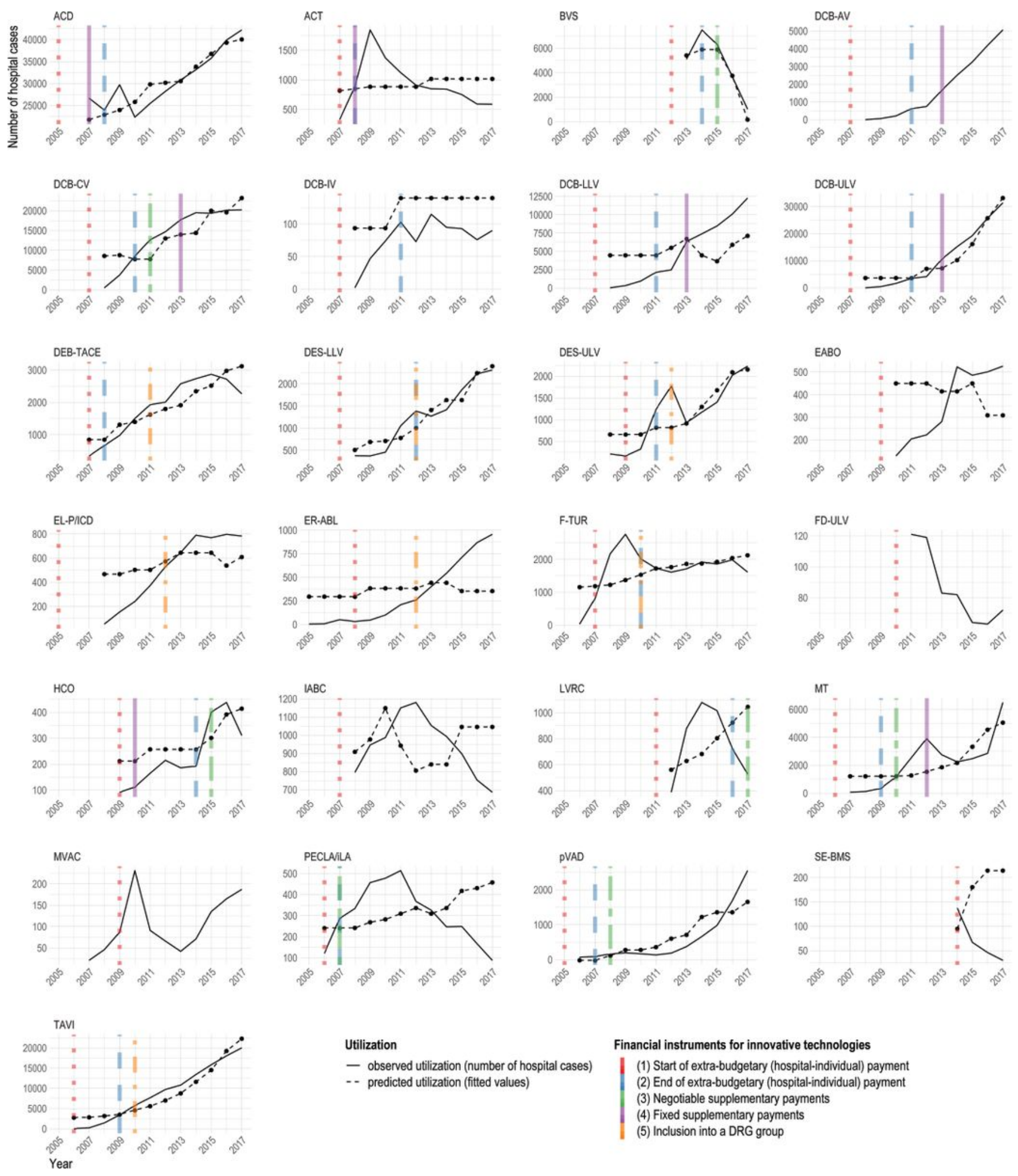

Financial instruments for innovative technologies

(1) Start of extra-budgetary (hospital-individual) payment

(2) End of extra-budgetary (hospital-individual) payment

(3) Negotiable supplementary payments

(4) Fixed supplementary payments

(5) Inclusion into a DRG group

\section{Figure 4}

Relationship between utilization, evidence, and funding: Ability of LoE 1-3 evidence to predict utilization Source: Created by the authors; Notes: Overlapping coloured lines mean ending of one and beginning of another reimbursement type; Fitted values are based on results of evidence but not on financial instrument; For sources of information on financial instruments and number of hospital cases see additional file 1 appendices 1 and 2; Abbreviations: ACD - Anticoagulation with citrate during dialysis; 
ACT - Adjustable continence therapy; BVS - Bioresorbable Vascular Scaffold in coronary vessels; DCB-AV Drug-coated balloon catheter in abdominal vessels; DCB-CV - Drug-coated balloon catheter in coronary vessels; DCB-IV - Drug-coated balloon catheter in intracranial vessels; DCB-LLV - Drug-coated balloon catheter in lower leg vessels; DCB-ULV - Drug-coated balloon catheter in upper leg vessels; DEB-TACE Drug-eluting beads for transarterial chemoembolization; DES-LLV - Implantation of a drug-eluting stent in lower leg vessels; DES-ULV - Implantation of a drug-eluting stent in upper leg vessels; EABO - Endoaortic balloon occlusion with extracorporeal circulation; EL-P/ ICD - Excimer laser extraction of pacemaker and defibrillator electrodes; ER-ABL - Cardiac event recorder after ablative measures for atrial fibrillation / atrial tachycardia; FD-ULV - Flow-diverter (Hemodynamically effective implant for endovascular treatment of peripheral aneurysms) in upper leg vessels; F-TUR - Fluorescence-assisted transurethral resection; HCO - Dialysis with high cut-off dialysis membrane; IABC - Bioactive coils for intracranial aneurysm therapy; LVRC - Lung volume reduction by insertion of coils; LoE - Level of evidence; MT - Intracranial endovascular mechanical thrombectomy; MVAC - Mitral valve annuloplasty with clamp; PECLA/ iLA Pumpless Extracorporeal Lung Assist/ Interventional Lung Assist; pVAD - Percutaneous ventricular assist device (Micro-axial blood pump); SE-BMS - Self-expanding bare metal stents in coronary vessels; TAVI Transcatheter aortic valve implantation

\section{Supplementary Files}

This is a list of supplementary files associated with this preprint. Click to download.

- Additionalfile1.pdf 